\title{
A Reference Point Method to Triple-Objective Assignment of Supporting Services in a Healthcare Institution
}

\author{
Bartosz Sawik ${ }^{\star}$
}

\begin{abstract}
This paper presents an application of mixed integer programming model for optimal allocation of workers among supporting services in a hospital. The services include logistics, inventory management, financial management, operations management, medical analysis, etc. The optimality criterion of the problem is to minimize operational costs of supporting services subject to some specific constraints. The constraints represent specific conditions for resource allocation in a hospital. The overall problem is formulated as a tripleobjective assignment model, where the decision variables represent the assignment of people to various jobs. A reference point approach with the Chebyshev metric is applied for the problem solution. The results of computational experiments modeled on a real data from a hospital in Lesser Poland are reported.
\end{abstract}

Keywords: reference point method, assignment problem, mixed integer programming, services operations management, healthcare planning.

Mathematics Subject Classification: 90B50 - management decision making, 90B80 - discrete location and assignment, 90C11 - mixed integer programming, 90C90 - applications of mathematical programming.

Revised: 01 December 2010.

\section{INTRODUCTION}

The assignment of service positions plays an important role in healthcare institutions. Poorly assigned positions in hospital departments or over-employment may result in increased expenses and/or degraded customer service. If too many workers are assigned, capital costs are likely to exceed the desirable value (Brandeau, 2004). The supporting services have a strong impact on performance of healthcare institutions such as hospitals. In hospital departments, the supporting services include financial management, logistics, inventory management, analytic laboratories, etc. This paper presents an application of operations research model for optimal supporting service

* Department of Applied Computer Science, Faculty of Management, AGH University of Science and Technology, Kraków, Poland, b_sawik@yahoo.com 
jobs allocation in a public healthcare institution. The optimality criterion of the problem is to minimize operations costs of a supporting service subject to some specific constraints. The constraints representing specific conditions for resource allocation in a hospital were modified, compared to previous publications (Sawik and Mikulik, 2008a; Sawik and Mikulik, 2008b; Sawik, 2008c; Sawik, 2010). The overall problem is formulated as a mixed integer program in the literature known as the assignment problem (Burrkard, 2008; Nemhauser, 1999). The binary decision variables represent the assignment of people to various services. This paper shows practical usefulness of mathematical programming approach to optimization of supporting services in healthcare institutions. The results of some computational experiments modeled after a real data from a selected Polish hospital are reported.

\section{DATA USED FOR COMPUTATIONS}

The real data from a selected Polish public healthcare institution from a one month period were used for computations. The data include 17 supporting service hospital departments, in which there are 74 types of supporting service jobs (Sawik and Mikulik, 2008a; Sawik and Mikulik, 2008b; Sawik, 2008c; Sawik, 2010). Permanent employment is defined as a percent of permanent post between $25 \%$ (0.25) to $100 \%$ (1.00) according to the size of a job position (part-time or full time) for a selected job in a selected department. It is possible that a department has four half time permanent employees and this could be for example an equivalent to two full time permanent employments. Supporting service departments in the hospital consist in total of 78.50 permanent employments with 192 workers employed before the optimization. Specific data consists of the average salaries for selected jobs in the departments defined as costs of assignment of workers to jobs. Furthermore, the average amount of money paid monthly for services in each department was used. Additional parameters include the number of permanent employments in each department and the size of permanent employments (i.e. $0.25,0.50,0.75,1.00)$ for each job defined as partial or full time. In addition, the minimum number of permanent employments for each job in each department was given, and the maximal number of positions which can be assigned to a single worker.

Table 1 presents the number of workers and service jobs in the hospital departments and the total number of workers in all departments before the optimization.

Table 1. Number of workers and service jobs in the hospital departments before optimization

\begin{tabular}{lcc}
\hline $\begin{array}{c}\text { Supporting service } \\
\text { departments }\end{array}$ & $\begin{array}{c}\text { Number of } \\
\text { workers }\end{array}$ & $\begin{array}{c}\text { Number of } \\
\text { jobs }\end{array}$ \\
\hline Attorneys-at-law & 4 & 2 \\
Law Regulation & 7 & 3 \\
Technical Executive & 4 & 4 \\
Business Executive & 8 & 5 \\
\hline
\end{tabular}


Table 1. (continued)

\begin{tabular}{lcc}
\hline Information & 7 & 4 \\
Material Monitoring & 13 & 5 \\
Sterilization & 27 & 5 \\
Hospital Pharmacy & 20 & 11 \\
Economy & 21 & 5 \\
Technical & 11 & 5 \\
Medical Equipment & 8 & 4 \\
Distribution & 6 & 3 \\
Heating and Air-condition & 11 & 4 \\
Ventilation and Air-condition & 8 & 4 \\
Medical Bottled Gases & 6 & 2 \\
Power & 15 & 3 \\
Central Heating & 16 & 5 \\
\hline All departments & 192 & 74 \\
\hline
\end{tabular}

Table 2 shows the number of types of permanent employments and the maximum amount of money paid for services in the hospital departments before optimization.

Table 2. Number of permanent employments and the maximum amount of money paid for services in the hospital departments before optimization

\begin{tabular}{lcr}
\hline $\begin{array}{l}\text { Supporting service } \\
\text { departments }\end{array}$ & $\begin{array}{c}\text { Number of types } \\
\text { of permanent employments }\end{array}$ & $\begin{array}{c}\text { Amount of money paid } \\
\text { for services }\end{array}$ \\
\hline Attorneys-at-law & 2.5 & 7,950 \\
Law Regulation & 7 & 16,100 \\
Technical Executive & 4 & 7,150 \\
Business Executive & 5 & 15,450 \\
Information & 4 & 16,100 \\
Material Monitoring & 5 & 27,150 \\
Sterilization & 5 & 41,500 \\
Hospital Pharmacy & 11 & 43,400 \\
Economy & 5 & 31,360 \\
Technical & 5 & 20,950 \\
Medical Equipment & 4 & 17,500 \\
Distribution & 3 & 13,600 \\
Heating and Air-condition & 4 & 21,200 \\
Ventilation and Air-condition & 4 & 16,650 \\
Medical Bottled Gases & 2 & 11,400 \\
Power & 3 & 31,050 \\
Central Heating & 5 & 29,250 \\
\hline All departments & 78.5 & 367,760 \\
\hline
\end{tabular}




\section{REFERENCE POINT METHOD}

Consider the following multi-objective problem:

$$
\begin{array}{cl}
\text { Maximize } & z_{l}=f_{l}(x) \\
& z_{q}=f_{q}(x) \\
\text { subject to } & x \in X, x \geqslant 0,
\end{array}
$$

where $X \subset \Re^{n}$ denotes the non-convex set of feasible solutions defined by a set of functional constraints - linear inequalities.

The reference point method is based on the Chebyshev metric (Alves, 2007; Bowman, 1976). Let us denote by $\|f(x)-f\|_{\beta}$ the $\beta$-weighted Chebyshev metric, i.e. $\min _{1 \leqslant l \leqslant q}\left\{\beta_{l}\left|f_{l}(x)-\underline{f}\right|\right\}$, where $\beta_{l} \geqslant 0 \quad \forall \bar{l}, \sum_{l=1}^{q} \beta_{l}=1$, and $f$ denotes a reference point of the criteria space. Considering $f(x)>f$ for all $x \in \bar{X}$, it has been proven (Bowman, 1976) that the parameterization on $\bar{\beta}$ of $\min _{x \in X}\left\|f_{l}(x)-f\right\|_{\beta}$ generates the non-dominated set of solutions.

The program $\min _{x \in X}\left\|f_{l}(x)-f\right\|_{\beta}$ may yield weakly non-dominated solutions, which can be avoided by considering the augmented weighted Chebyshev program:

$$
\begin{array}{ll}
\text { Minimize } & \delta+\gamma \sum_{l=1}^{q} f_{l}(x) \\
\text { subject to } & \beta_{l}\left(f_{l}(x)-\underline{f}\right) \leqslant \delta, \quad 1 \leqslant l \leqslant q \\
& x \in X \\
& \delta \geqslant 0,
\end{array}
$$

where $\gamma$ is a small positive value. It has been proven (Ehrgott, 2000; Steuer, 1986) that there always exists $\gamma$ small enough that enable to reach all the non-dominated set for the finite-discrete and polyhedral feasible region cases (Alves, 2007). The reference points are defined as ideal values of objective functions.

\section{PROBLEM FORMULATION}

Mathematical programming approach deals with optimization problems of maximizing or minimizing a function of many variables subject to inequality and equality constraints and integrality restrictions on some or all of the variables. In particular, $0-1$ variables represent binary choice. Therefore, the model presented in this paper is defined as a mixed integer programming problem.

Suppose there are $m$ people and $p$ jobs, where $m \neq p$. Each job must be done by at least one person; also, each person can do at least, one job. The cost of person $i$ doing job $k$ is $c_{i k}$. The problem objective is to assign the people to the jobs so as to minimize the total cost of completing all of the jobs.

The optimality criterion of the defined problem is to minimize operations costs of a supporting service subject to some specific constraints. The constraints represent specific conditions for resource allocation in a hospital. The overall problem is 
formulated as a modified assignment problem. The decision variables represent the assignment of people among various services. Compared to previously published papers (Sawik and Mikulik, 2008a; Sawik and Mikulik, 2008b; Sawik, 2008c; Sawik, 2010) decision variables and constraints were modified.

Table 3 shows the notation used in this section.

Table 3. Notation

\begin{tabular}{|c|c|}
\hline \multicolumn{2}{|r|}{ Indices } \\
\hline$i$ & - worker, $i \in I=\{1, \ldots, m\}$ \\
\hline$j$ & - supporting service hospital department, $j \in J=\{1, \ldots, n\}$ \\
\hline$k$ & - type of supporting service job $k \in K=\{1, \ldots, p\}$ \\
\hline \multicolumn{2}{|r|}{ Input parameters } \\
\hline$c_{i k}$ & - cost of an assignment of a worker $i$ to job $k$ (i.e. monthly salary); \\
\hline$C_{j}$ & - maximal monthly budget for salaries in a department $j$ \\
\hline$e_{k}$ & $\begin{array}{l}- \text { size of permanent (partial or full time) employment for job } k \\
\left.\quad \text { (i.e. } e_{k}=0.25 \text { or } 0.50 \text { or } 0.75 \text { or } 1.00\right)\end{array}$ \\
\hline$E_{j}$ & - maximal number of permanent employments in a department $j$ \\
\hline$h_{j k}$ & - minimal number of permanent employments for job $k$ in a department $j$; \\
\hline$\beta_{i}$ & - weight of the objective function $f_{i}^{o p t}, i=1,2,3$ \\
\hline$\gamma$ & - small positive value; \\
\hline$f_{1}^{o p t}$ & $\begin{array}{l}\text { - ideal solution value of number of workers selected for an assignment to any job } \\
\text { in any department; }\end{array}$ \\
\hline$f_{2}^{o p t}$ & - ideal solution value of operational costs of the supporting services; \\
\hline$f_{3}^{o p t}$ & $\begin{array}{l}\text { - ideal solution value of number of permanent employments for all jobs in all } \\
\text { departments; }\end{array}$ \\
\hline \multicolumn{2}{|r|}{ Decision variables } \\
\hline$x_{i j k}$ & - 1 if worker $i$ is assigned to job $k$ in department $j, 0$ otherwise; \\
\hline$y_{i}$ & - 1 if worker $i$ is assigned to any job in any department, 0 otherwise; \\
\hline$g_{j k}$ & - number of permanent employments for job $k$ in department $j$ \\
\hline$\delta$ & - deviation from the reference solutions. \\
\hline
\end{tabular}

\section{OPTIMIZATION MODEL}

The problem of optimal assignment is formulated as a triple objective integer program, which allows commercially available software (e.g. AMPL/CPLEX (Fourer, 1990)) to be applied for solving practical instances. 
Minimize:

$$
\delta+\gamma\left(\sum_{i=1}^{m} y_{i}+\sum_{i=1}^{m} \sum_{j=1}^{n} \sum_{k=1}^{p} c_{i k} x_{i j k}+\sum_{j=1}^{n} \sum_{k=1}^{p} g_{j k}\right)
$$

subject to

$$
\begin{aligned}
& \beta_{1}\left(\sum_{i=1}^{m} y_{i}-f_{1}^{o p t}\right) \leqslant \delta \\
& \beta_{2}\left(\sum_{i=1}^{m} \sum_{j=1}^{n} \sum_{k=1}^{p} c_{i k} x_{i j k}-f_{2}^{o p t}\right) \leqslant \delta \\
& \beta_{3}\left(\sum_{j=1}^{n} \sum_{k=1}^{p} g_{j k}-f_{3}^{o p t}\right) \leqslant \delta \\
& \sum_{i=1}^{m} \sum_{k=1}^{p} c_{i k} x_{i j k} \leqslant C_{j}, \quad j \in J \\
& \sum_{i=1}^{m} \sum_{k=1}^{p} e_{k} x_{i j k} \leqslant E_{j}, \quad j \in J \\
& \sum_{j=1}^{n} \sum_{k=1}^{p} e_{k} x_{i j k} \leqslant 2, \quad i \in I \\
& \sum_{i=1}^{m} x_{i j k} \geqslant h_{j k}, \quad j \in J, k \in K \\
& g_{j k} \geqslant h_{j k}, \quad j \in J, k \in K \\
& \frac{\sum_{j=1}^{n} \sum_{k=1}^{p} x_{i j k}}{\sum_{j=1}^{n} E_{j}} \leqslant y_{i} \leqslant \sum_{j=1}^{n} \sum_{k=1}^{p} x_{i j k}, \quad i \in I \\
& x_{i j k} \in\{0,1\}, \quad i \in I, j \in J, k \in K \\
& y_{i} \in\{0,1\}, \quad i \in I \\
& g_{j k} \geqslant 0, \quad j \in J, k \in K \\
& \delta \geqslant 0
\end{aligned}
$$

The optimality criterion (1) is to minimize total number of workers selected for an assignment to any job in any department and to minimize operational costs of the supporting services and finally to minimize the number of permanent employments for all jobs in all departments. 
Constraints (2), (3) and (4) define the deviation from the reference solution. Constraint (5) ensures that the cost of workers assignment to service jobs in each department must be less than or equal to maximum amount of money paid regularly for services in the department (monthly salaries). Constraint (6) ensures that the total size of permanent (partial or full time) employment for each job (i.e. 0.25 or 0.50 or 0.75 or 1.00) in each department must be less than or equal to the maximal number of permanent employments in this department. Constraint (7) ensures that each worker can be assigned to a maximum two full time positions in parallel. Constraint (8) is responsible for an assignment of workers on at least minimal level requirements, e.g. the number of permanent employments on a selected service jobs.

Constraint (9) is responsible for obtaining only the results which will not lead to solutions without any assignment to some jobs. It compares real and minimal accepted number of permanent employments.

Constraint (10) ensures that worker $i$ is taken $\left(y_{i}=1\right)$ if he gets assignment to any job in any department $\left(x_{i j k}=1\right.$ for any $j$ and $k$ ). Constraint (10) defines the relation between binary decision variables $x_{i j k}$ and $y_{i}$. Constraints (11) and (12) define binary decision variables $x_{i j k}$ and $y_{i}$. Constraints (13) and (14) define continuous decision variables $g_{j k}$ and $\delta$.

\section{COMPUTATIONAL RESULTS}

In this section numerical examples and some computational results are presented to illustrate possible applications of the proposed formulations of integer programming of optimal assignment of service positions. Selected problem instances with the examples are modeled on a real data from a Polish hospital.

In the computational experiments the historical data is considered. Computational time takes only a fraction of a second to find optimal solution if any exists. The computational experiments have been performed using AMPL programming language (Fourer, 1990) and the CPLEX v.11 solver (with the default settings) on a laptop with Intel(C) Core 2 Duo T9300 processor running at $2.5 \mathrm{GHz}$ and with 4 GB RAM.

Table 4 presents the reference point values of parameters for computational experiments with the method optimization model and the size of adjusted problem.

Table 4. The values of parameters for computational experiments and the size of adjusted problem

\begin{tabular}{ccccccc}
\hline Scenario & $f_{1}^{\text {opt }}$ & $f_{2}^{\text {opt }}$ & $f_{3}^{\text {opt }}$ & $\begin{array}{c}\text { All } \\
\text { variables }\end{array}$ & $\begin{array}{c}\text { Binary } \\
\text { variables }\end{array}$ & Constraints \\
\hline A & 70 & 150000 & 75 & 4448 & 3188 & 566 \\
B & 110 & 200000 & 105 & 4416 & 3156 & 526 \\
C & 130 & 250000 & 120 & 4416 & 3156 & 526 \\
D & 160 & 300000 & 155 & 4404 & 3144 & 512 \\
$\gamma=0.01$ & $\beta_{1}=0.33 \cdot 1000$ & \multicolumn{2}{c}{$\beta_{2}=0.34$} & $\beta_{3}=0.33 \cdot 1000$ \\
\hline
\end{tabular}


Table 5 presents comparison of computational results with alternative scenarios.

Table 5. Comparison of computational results with alternative scenarios

\begin{tabular}{crcccccc}
\hline Scenario & $\delta$ & $\begin{array}{c}\text { Number } \\
\text { of workers }\end{array}$ & $\begin{array}{c}\text { Operational } \\
\text { costs } \\
\text { PLN }\end{array}$ & $\begin{array}{c}\text { Number } \\
\text { of permanent } \\
\text { employments }\end{array}$ & $\begin{array}{c}\text { MIP } \\
\text { simplex } \\
\text { iterations }\end{array}$ & $\begin{array}{c}\text { B\&B } \\
\text { nodes }\end{array}$ & $\begin{array}{c}\text { CPU } \\
\text { seconds }\end{array}$ \\
\hline A & 1320.00 & 74 & 147,201 & 71.50 & 297 & 6 & 0.265 \\
B & 3842.51 & 109 & 211,302 & 105.75 & 161 & 0 & 0.202 \\
C & 330.00 & 131 & 248,952 & 121.75 & 433 & 0 & 0.296 \\
D & 1802.51 & 162 & 305,302 & 159.00 & 310 & 0 & 0.171 \\
\hline
\end{tabular}

As it has been recommended by the hospital managers four different scenarios of the assignment have been implemented. In scenario A, a minimal number of people is employed in each supporting service department so that each type of a job has at least one worker assigned. This rule is implemented in input parameter $h_{j k}$. In scenario B at least two workers were assigned to each job. Scenario C secured the level of supporting service workers. In each department there are at least two workers assigned to each job, but for some special cases, more than two workers are assigned to each job. Finally, scenario D presents the optimal assignment of workers to jobs with a high service level with all currently employed workers. The results obtained have indicated the problem of over-employment in the hospital.

In Table 5, column "MIP simplex iteration" shows the number of mixed integer programming simplex iterations until the solution is presented. Column "B\&B nodes" shows the number of searched nodes in the branch and bound tree until presented solution.

In Table 6 the number of workers assigned to the supporting service hospital departments and the number of permanent employments is presented.

Table 6. Number of workers assigned and number of permanent employments in departments

\begin{tabular}{|c|c|c|c|c|c|c|c|c|}
\hline \multirow{3}{*}{$\begin{array}{l}\text { Supporting service } \\
\text { departments }\end{array}$} & \multicolumn{8}{|c|}{ Assignment of workers in departments according to scenario } \\
\hline & \multicolumn{2}{|r|}{ A } & \multicolumn{2}{|r|}{$\mathrm{B}$} & \multicolumn{2}{|r|}{$\mathrm{C}$} & \multicolumn{2}{|c|}{$\mathrm{D}$} \\
\hline & workers & $\begin{array}{l}\text { permanent } \\
\text { employ- } \\
\text { ments }\end{array}$ & workers & $\begin{array}{c}\text { permanent } \\
\text { employ- } \\
\text { ments }\end{array}$ & workers & $\begin{array}{c}\text { permanent } \\
\text { employ- } \\
\text { ments }\end{array}$ & workers & $\begin{array}{c}\text { permanent } \\
\text { employ- } \\
\text { ments }\end{array}$ \\
\hline Attorneys-at-law & 2 & 1.5 & 3 & 2.5 & 3 & 2 & 3 & 2.5 \\
\hline Law Regulation & 3 & 3 & 5 & 5 & 5 & 4 & 5 & 5 \\
\hline Technical Executive & 4 & 3.5 & 4 & 3.5 & 4 & 3.5 & 4 & 3.5 \\
\hline Business Executive & 5 & 5 & 6 & 6 & 6 & 6 & 7 & 7 \\
\hline Information & 4 & 3.5 & 5 & 4.5 & 5 & 4.5 & 6 & 5.5 \\
\hline Material Monitoring & 5 & 5 & 7 & 7 & 8 & 8 & 11 & 11 \\
\hline Sterilization & 5 & 5 & 8 & 8 & 14 & 13.5 & 21 & 21 \\
\hline
\end{tabular}


Table 6. (continued)

\begin{tabular}{|c|c|c|c|c|c|c|c|c|}
\hline Hospital Pharmacy & 11 & 10.5 & 15 & 14.5 & 17 & 14.5 & 19 & 18.5 \\
\hline Economy & 5 & 5 & 9 & 9 & 14 & 13.5 & 18 & 18 \\
\hline Technical & 5 & 5 & 8 & 8 & 8 & 7.5 & 9 & 9 \\
\hline Medical Equipment & 4 & 4 & 6 & 5.75 & 6 & 5.75 & 7 & 6.5 \\
\hline Distribution & 3 & 3 & 5 & 5 & 5 & 4.5 & 5 & 5 \\
\hline $\begin{array}{l}\text { Heating and Air- } \\
\text { condition }\end{array}$ & 4 & 4 & 5 & 5 & 7 & 7 & 9 & 9 \\
\hline $\begin{array}{l}\text { Ventilation and Air- } \\
\text { condition }\end{array}$ & 4 & 3 & 6 & 6 & 6 & 5.5 & 7 & 7 \\
\hline $\begin{array}{l}\text { Medical Bottled } \\
\text { Gases }\end{array}$ & 2 & 2 & 3 & 3 & 4 & 3.5 & 5 & 5 \\
\hline Power & 3 & 3 & 5 & 5 & 8 & 8 & 12 & 12 \\
\hline Central Heating & 5 & 4.5 & 9 & 8 & 11 & 10.5 & 14 & 13.5 \\
\hline All departments & 74 & 71.5 & 109 & 105.75 & 131 & 121.75 & 162 & 159 \\
\hline
\end{tabular}

${ }^{*}$ Scenarios A, B, C and D considered subject to hospital authority requirements

\section{CONCLUSIONS}

Operations research techniques, tools and theories have long been applied to a wide range of issues and problems in healthcare. This paper proves the practical usefulness of mathematical programming approach to optimization of supporting service in a hospital. The results of computational experiments modeled after a real data from a hospital in Lesser Poland indicate that the number of hired workers can be reduced in almost all departments of the hospital.

The proposed modified multi-objective assignment problem and a reference point approach can be easily implemented for management of supporting services in another institution, not only healthcare. Obtained results consist of the monthly expenses for salaries, the number of workers and the amount of permanent employments needed for jobs in all considered supporting service departments.

Computational time takes only a fraction of a second to find the optimal solution because of a relatively small size of the input data. Presented optimization model is NP-hard, but computable. Implementation of reference point method ensures to obtain results with non-dominated set of solutions. The global optimums for considered three objective functions are presented.

\section{ACKNOWLEDGEMENTS}

The author is grateful to an anonymous reviewer for reading the manuscript very carefully and providing constructive comments which helped to substantially improve this paper. This work has been partially supported by Polish Ministry of Science and Higher Education (MNISW) grant for PhD Research \#N N519 405934 and by AGH grant. 


\section{REFERENCES}

Alves, M.J., Climaco, J., 2007. A review of interactive methods for multiobjective integer and mixed-integer programming, European Journal of Operational Research, Vol. 180, pp. $99-115$.

Bowman Jr, V.J., 1976. On the relationship of the Chebyshev norm and the efficient frontier of multi-criteria objectives, [in:] Thiriez H., Zionts S. (Eds.) Multiple Criteria Decision Making, Lecture Notes in Economics and Mathematical Systems, Vol. 130. SpringerVerlag, Berlin, Germany, pp. 76-86.

Brandeau, M.L., Sainfort, F., Pierskalla, W.P., 2004. Operations Research and Health Care. Kluwer Academic Publishers, Boston, USA.

Burrkard, R., Dell'amico, M., Martello, S., 2008. Assignment Problems. SIAM, Philadelphia, USA.

Ehrgott, M., 2000. Multicriteria Optimization. Second edition, Springer, Berlin, Germany.

Fourer, R., Gay, D.M., Kernighan, B.W., 1990. A Modeling Language for Mathematical Programming, Management Science, Vol. 36, pp. 519-554.

Nemhauser, G.L., Wolsey, L.A., 1999. Integer and Combinatorial Optimization, John Wiley \& Sons, Toronto, Canada.

Sawik, B., 2010. Reference Point Approach to Assignment of Supporting Services in a Healthcare Institution, chapter [in:] Swierniak A., Krystek J. (Eds.) Automatics of Discrete Processes, Theory and Applications, Vol. 2, Monographic of the Silesian University of Technology, PKJS, Gliwice, Poland, pp. 187-196.

Sawik, B., Mikulik, J., 2008a. An Optimal Assignment of Workers to Supporting Services in a Hospital, Polish Journal of Medical Physics and Engineering, Vol. 14(4), 197-206.

Sawik, B., Mikulik, J., 2008b. Model for Supporting Service Optimization in a Public Health Care Institution, EFOMP council and officer's meeting, 14th general assembly of the Polish Society of Medical Physics, European Conference Medical Physics and Engineering 110 years after the discovery of Polonium and Radium, 17-21 September 2008, Kraków, AGH, Polish Academy of Science, Poland.

Sawik, B., 2008c. Bi-Objective Integer Programming Approach to Optimal Assignment of Supporting Services in a Health-Care Institution. The 21st Conference of the European Chapter on Combinatorial Optimization (ECCO XXI) May 29-31, 2008, Dubrovnik, Croatia.

Steuer, R.E., 1986. Multiple Criteria Optimization: Theory, Computation and Application, John Wiley \& Sons, New York, USA. 